\title{
Hemodynamic Effects of Environmental Hyperthermia in Stage 18, 21, and 24 Chick Embryos
}

\author{
MAKOTO NAKAZAWA, SACHIKO MIYAGAWA, ATSUYOSHI TAKAO, EDWARD B. CLARK, \\ AND NORMAN HU \\ Department of Pediatric Cardiology, The Heart Institute of Japan, Tokyo Women's Medical College, Tokyo, \\ Japan, and Division of Pediatric Cardiology, Department of Pediatrics, School of Medicine, The Johns Hopkins \\ University, Baltimore, Maryland 21205
}

\begin{abstract}
Environmental hyperthermia is a hazard to the poikilothermic chick embryo. We studied effects of hyperthermia on mean vitelline arterial blood pressure and mean dorsal aortic blood flow in stage 18, 21, and 24 chick embryos. The pressure was measured with a servo-null micropressure system, and the blood flow was measured with a $20 \mathrm{MHz}$ pulsed Doppler flowmeter. Temperature was monitored with a needle thermoprobe positioned adjacent to the embryo. Data were obtained at $37^{\circ} \mathrm{C}$, after warming to $40^{\circ} \mathrm{C}$, and then after cooling to $37^{\circ} \mathrm{C}$. At stage 21 , the pressure increased from $0.96 \pm 0.05$ ( \pm SE) to 1.04 $\pm 0.06 \mathrm{~mm} \mathrm{Hg}$ on warming and returned from $1.05 \pm 0.04$ to $0.87 \pm 0.04 \mathrm{~mm} \mathrm{Hg}$ on cooling. Pressure measurements during warming and cooling were performed in two separate groups of embryos because of technical problems. The blood flow, studied using different groups of the embryo from the pressure study, also increased from $0.65 \pm 0.06$ to $0.75 \pm 0.06 \mathrm{~mm}^{3} / \mathrm{s}$ on warming and returned to $0.56 \pm$ $0.05 \mathrm{~mm}^{3} / \mathrm{s}$. The heart rate increased from $173 \pm 2$ to 211 \pm 3 at $40^{\circ} \mathrm{C}$ and returned to $170 \pm 3$ at $37^{\circ} \mathrm{C}$. Stroke volume (flow/heart rate) did not change during the temperature variation. Vascular resistance, the quotient of pressure to blood flow obtained by a ratio analysis, changed from $1.53 \pm 0.33$ (median $\pm 95 \%$ confidence interval) to $1.42 \pm 0.29 \mathrm{~mm} \mathrm{Hg} / \mathrm{mm}^{3} / \mathrm{s}$ on warming and changed to $1.60 \pm 0.32 \mathrm{~mm} \mathrm{Hg} / \mathrm{mm}^{3} / \mathrm{s}$ on cooling. Similar results were obtained at stages 18 and 24 . The data indicate that the primary effect of hyperthermia is increasing heart rate, bringing about the increase of cardiac output and arterial pressure. (Pediatr Res 20: 1213-1215, 1986)
\end{abstract}

Evidence is now being accumulated on the functional development of the cardiovascular system, which should help understand normal or abnormal organogenesis. We have reported the effects of environmental hypothermia on hemodynamics of the chick embryo $(1,2)$. High temperature during early stages of development causes embryo death or malformations of various organs including the cardiovascular system $(3,4)$. Therefore, we studied the hemodynamic effect of environmental hyperthermia in the chick embryo. We found that hyperthermia brought about the increase of cardiac output through the increase of heart rate, which resulted in the increase of vitelline arterial blood pressure.

Received November 20. 1984; accepted April 21, 1986.

Address for correspondence Makoto Nakazawa. M.D.. Department of Pediatric Cardiology. The Heart Institute of Japan. Tokyo Women's Medical College. 10 Kawada-cho, Shinjuku-ku. Tokvo 162. Japan.

\section{MATERIALS AND METHODS}

One hundred twenty-eight embryos of the white Leghorn chick were used at the Hamburger-Hamilton stages 18, 21, and 24 (5). We used the same experimental procedures as previously reported $(1,2)$. After exposing the embryo and the vitelline arteries, the dorsal aortic blood flow was measured with a $20 \mathrm{MHz}$ pulsed Doppler flowmeter with a probe of $1 \mathrm{~mm}$ diameter. The vitelline arterial blood pressure was measured by a servo-null micropressure system (WP Instruments model 900) with a glass pipette of a tip diameter of $5 \mu \mathrm{m}$. Data for pressure and flow were obtained in separate groups of embryos because of technical difficulty.

Temperature was monitored by a needle thermoprobe, a tip of which was inserted just underneath or very close to the embryo (Fig. 1). A heat lamp was used to control the temperature. To avoid drying the embryo and vitelline circulation, we limited an opening of the shell membrane as small as possible and pipetted $0.3-0.5 \mathrm{ml}$ chick Ringer solution. The latter procedure had been reported to have no hemodynamic effect in this preparation (1).

Data were obtained at $37^{\circ} \mathrm{C}$, and the embryo was warmed to $40^{\circ} \mathrm{C}$ when data were again recorded. Then temperature was lowered to $37^{\circ} \mathrm{C}$ where pressure and flow were measured. The flow data were recorded continuously during the temperature change in each embryo. But the pressure study was performed in two separate groups of the embryo at each stage. One group was during warming and the other during cooling. This was because the ionic balance between chick embryo blood and $1 \mathrm{~N}$ $\mathrm{KCl}$ solution within the glass pipette could change with time,

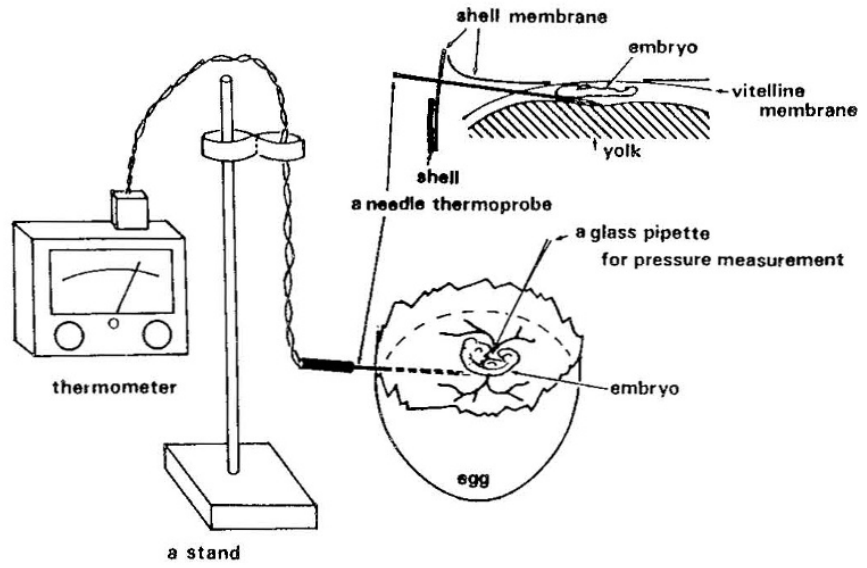

Fig. 1. Positioning of a needle thermoprobe. Upper right, cross-sectional view details relation of needle probe to embryo. 
thus causing a shift of zero balance of the system. The number of embryos used in each protocol was presented in Table 1. The arterial vascular resistance was calculated from the flow and pressure data by a ratio analysis (6). Statistical analysis was performed by analysis of variance or repeated-measures analysis of variance and Newman-Keuls test; $p<0.05$ was accepted as significant.

\section{RESULTS}

Heart rate increased by $17-22 \%$ at the high temperature and returned to base line on cooling to $37^{\circ} \mathrm{C}$ (Table 2).

On warming to $40^{\circ} \mathrm{C}$, the mean arterial blood pressure increased from $0.80 \pm 0.02( \pm \mathrm{SE})$ to $0.92 \pm 0.03 \mathrm{~mm} \mathrm{Hg}$ in stage $18(n=16)$, from $0.96 \pm 0.05$ to $1.04 \pm 0.06 \mathrm{~mm} \mathrm{Hg}$ in stage $21(n=14)$, and from $1.15 \pm 0.05$ to $1.34 \pm 0.06 \mathrm{~mm} \mathrm{Hg}$ in stage $24(n=13)$. This parameter decreased to base line on cooling to $37^{\circ} \mathrm{C}$ (Fig. 2).

The dorsal aortic blood flow increased on warming from 0.40 \pm 0.03 to $0.46 \pm 0.03 \mathrm{~mm}^{3} / \mathrm{s}$ and returned to $0.36 \pm 0.03$ $\mathrm{mm}^{3} / \mathrm{s}$ on cooling in stage $18(n=13)$; from $0.65 \pm 0.06$ to 0.75 $\pm 0.06 \mathrm{~mm}^{3} / \mathrm{s}$, then to $0.56 \pm 0.05 \mathrm{~mm}^{3} / \mathrm{s}$ in stage $21(n=18)$,

Table 1. Number of embryos in each protocol

\begin{tabular}{cccc}
\hline & & \multicolumn{2}{c}{ Pressure study } \\
\cline { 3 - 4 } & Flow study & Warm-up & Cool-down \\
\hline Stage 18 & 13 & 16 & 12 \\
Stage 21 & 18 & 14 & 16 \\
Stage 24 & 12 & 13 & 14 \\
\hline
\end{tabular}

Table 2. Changes in heart rate*

\begin{tabular}{cccc}
\hline Temperature $\left({ }^{\circ} \mathrm{C}\right)$ & Stage 18 & Stage 21 & Stage 24 \\
\hline Pressure study & & & \\
37 & $162 \pm 4$ & $174 \pm 3$ & $192 \pm 7$ \\
40 & $189 \pm 3$ & $204 \pm 4$ & $227 \pm 7$ \\
40 & $192 \pm 4$ & $203 \pm 5$ & $225 \pm 5$ \\
37 & $159 \pm 4$ & $167 \pm 4$ & $187 \pm 5$ \\
& & & \\
Flow study & $163 \pm 3$ & $173 \pm 2$ & $186 \pm 2$ \\
37 & $196 \pm 4$ & $211 \pm 3$ & $224 \pm 5$ \\
40 & $159 \pm 4$ & $170 \pm 3$ & $188 \pm 3$ \\
\hline
\end{tabular}

* Mean \pm SE.

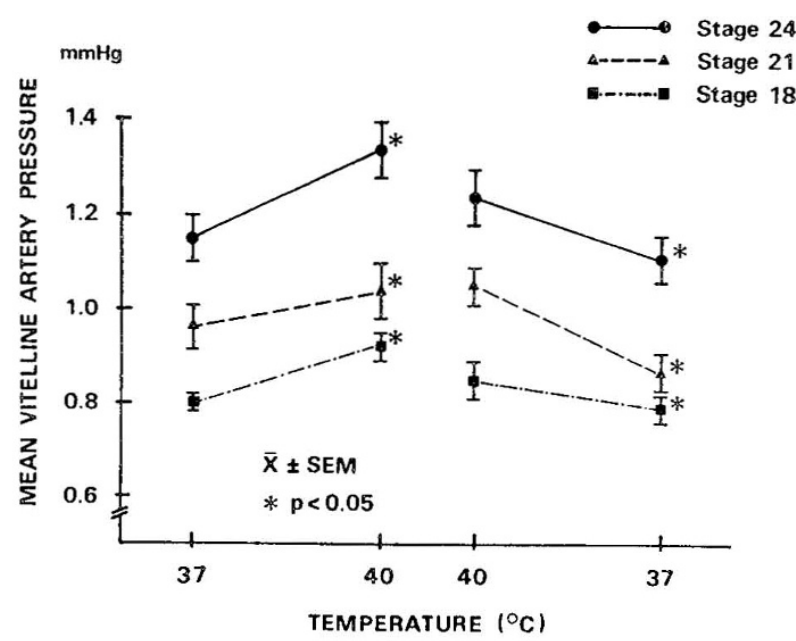

Fig. 2. Effect of hyperthermia on mean vitelline arterial blood pressure. Pressure increased in 14 of 16 embryos in stage 18 , in 10 of 14 in stage 21 , and in 11 of 13 in stage 24 , whereas it decreased in only one embryo in each stage. These data resulted in a statistically significant change in each stage, although the amount change was very small.

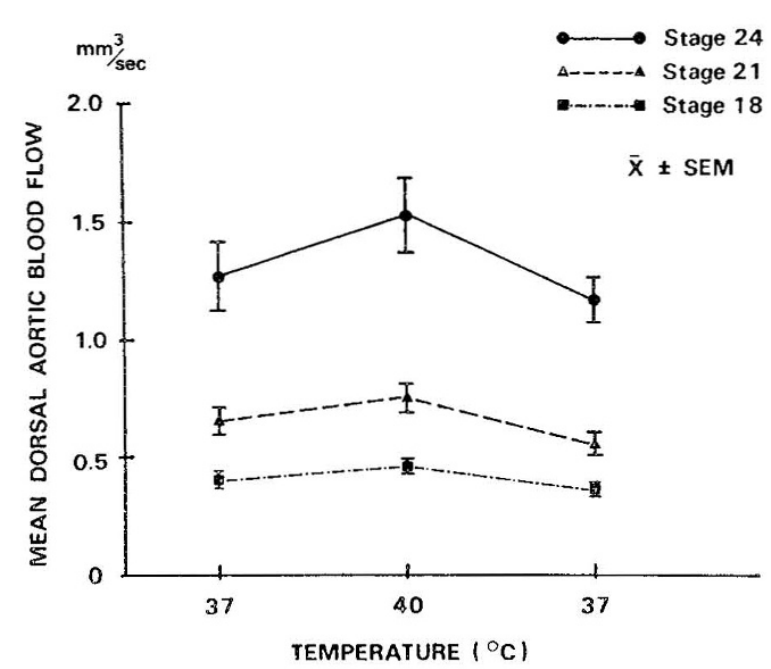

Fig. 3. Effect of hyperthermia on mean dorsal aortic blood flow. Flow increased significantly $(p<0.05)$ in each stage.

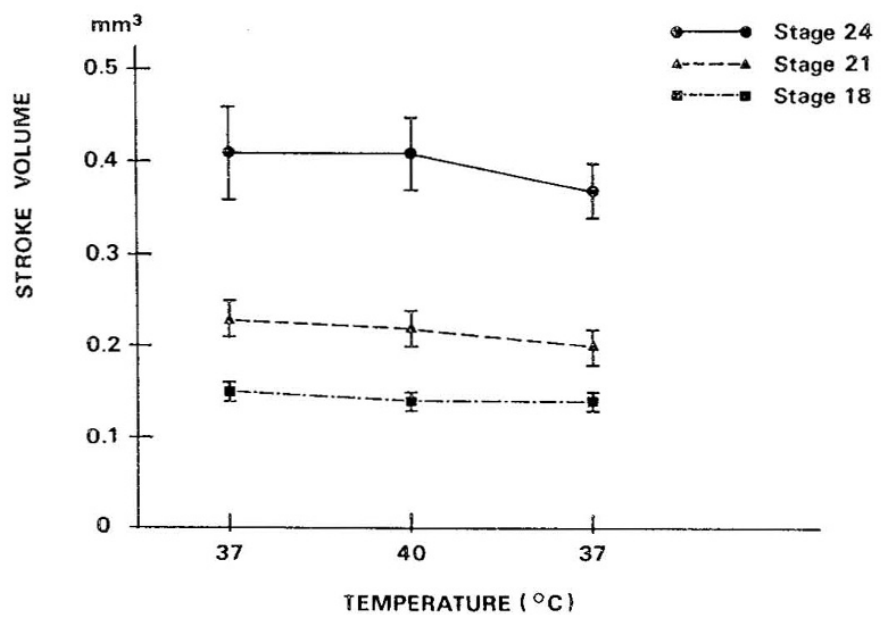

Fig. 4. Stroke volume (mean dorsal aortic flow/heart rate) did not significantly change during temperature change.
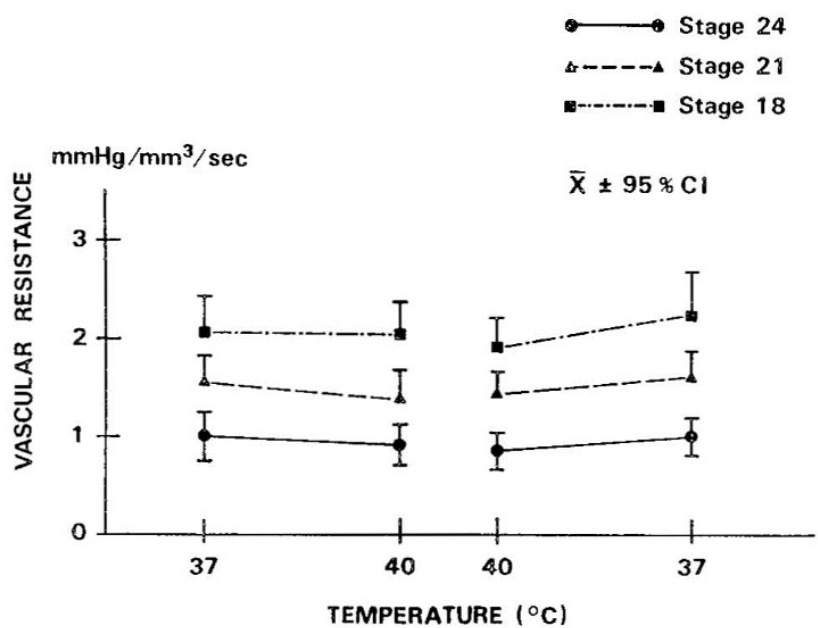

Fig. 5. Vitelline arterial vascular resistance showed no statistically significant changes.

and from $1.27 \pm 0.15$ to $1.53 \pm 0.16 \mathrm{~mm}^{3} / \mathrm{s}$, then to $1.17 \pm 0.10$ $\mathrm{mm}^{3} / \mathrm{s}$ in stage $24(n=12)$, respectively (Fig. 3). The stroke volume (dorsal aortic blood flow $\times 60 /$ heart rate) was not significantly altered by the temperature change (Fig. 4).

The change of vitelline arterial vascular resistance was not statistically significant (Fig. 5). 


\section{DISCUSSION}

The present study demonstrated that the increase in environmental temperature brought about the increase of dorsal aortic blood flow. The flow obtained at the dorsal aorta did not include flows to the head and myocardium, thus underestimating cardiac output (7). We assumed that the distribution of the systemic circulation of the embryo was constant during the change of temperature. Then we could conclude that environmental hyperthermia resulted in increased cardiac output.

We also found that stroke volume was not altered by hyperthermia. These findings indicated that the increase of cardiac output was a result of the increase in heart rate. Heart rate of the chick embryo is sensitive to temperature variation $(1,2,8,9)$.

In the mature subject, environmental hyperthermia results in a reduction of blood pressure through peripheral vasodilation, and this is compensated by an increase in heart rate brought about by the autonomic reflex and by an increase in cardiac output partly through augmented emptying of the ventricle $(10$, 11).

In the present study on the embryo, the calculated peripheral vascular resistance showed no significant reduction during hyperthermia. The lack of statistical significance might be due to the wide range of $95 \%$ confidence intervals of the data because of the technical problem as described in "Materials and Methods." Yet the reduction of vascular resistance might be physiologically significant.

Conversely, the vasculature may not actually show any active response to hyperthermia as the statistics showed. In the stages of embryo we used, the cardiovascular innervation was not established (9); thus vascular smooth muscle might be already in fully relaxed state. If this were the case, any intervention could not actively dilate the vessels. In fact, a potent $\beta$-agonist, isoproterenol, caused an increase, but not a decrease, of peripheral vascular resistance (12). Hawkins et al. (13) reported that caffeine induced vasodilation (13). In their study, blood flow and pressure were increased by caffeine, so it could not be concluded that the vessels were actively dilated; but vasodilation was likely due to the increase in cardiac output.

The vascular bed of the embryo of these stages is responsive to vasoactive substances such as phenylephrine, norepinephrine, and isoproterenol $(12,14)$. It is also known that egg yolk contains epinephrine and norepinephrine (15); in addition, Wallace reported that the chick embryo started to produce serotonin as early as stage 10 (16). Thus the temperature change may have induced the release of these intrinsic substances that diffused into the embryonic circulation. The result that hyperthermia was not associated with a significant decrease of vascular resistance might be explained by speculation that passive vasodilatation due to increased cardiac output was counteracted by vasoconstriction brought about by the released vasoconstrictive substances.

Nilsen (4) reported that incubation at 41 and $42^{\circ} \mathrm{C}$ was associated with various cardiovascular malformations in the chick embryo. They included dilation of various vessels, congested and dilated microvascular segments in the pellucid area, perivascular swelling, cardiac deformations, and irregular defects in the endocardial lining of the cardiac bulb with streaks of fluorescent material used in the study within the wall. Although the experimental conditions between our study and the study of Nilsen were quite different, the increased blood flow and pressure could dilate the vessels and damage the ventricular wall through an increase of wall stress. Thus, the present data could explain part of the mechanisms of the observations made by Nilsen (4).

\section{REFERENCES}

1. Wispé J, Hu N, Clark EB 1983 Effect of environmental hypothermia on dorsal aortic blood flow in the chick embryo, stage 18 to 24. Pediatr Res 17:945948

2. Nakazawa M, Clark EB, Hu N, Wispé J 1985 Effect of environmental hypothermia on vitelline artery blood pressure and vascular resistance in the stage 18, 21 and 24 chick embryo. Pediatr Res 19:651-654

3. deLaCruz MV, Campillo-Sainz C, Munoz-Armas S 1966 Congenital heart defects in chick embryos subjected to temperature variation. Circ Res 18:257-262

4. Nilsen $N \emptyset 1984$ Vascular abnormalities due to hyperthermia in chick embryo. Teratology 30:237-251

5. Hamburger V, Hamilton HL 1951 A series of normal stages in the development of the chick embryo. J Morphol 88:49-92

6. Finney DJ 1978 Statistical method in biological assey. Charles Griffin, London, pp 80-82

7. Clark EB, Hu N 1982 Developmental hemodynamic changes in the chick embryo from stage 18 to 27 . Circ Res 51:810-815

8. Cohn AE 1927 Physiologic ontogeny: A. Chicken embryos. XIII. The temperature characteristics for the contraction rate of the whole heart. J Gen Physiol 10:369-375

9. Romanoff AL 1960 The Avian Embryo: Structure and Functional Development. MacMillan, New York

10. Rowell LB, Brengelman GL, Murray JA 1969 Cardiovascular responses to sustained high skin temperature in resting man. J Appl Physiol 27:673-680

11. Lees DE, Kim YD, Bull JM, Whang-Peng J, Schuette W, Smith R, Macnamara TE 1980 Anesthetic management of whole-body hyperthermia for the treatment of cancer. Anesthesiol 52:418-428

12. Clark EB, Hu N, Dooley JB 1985 The effect of isoproterenol on cardiovascular function in the stage 24 chick embryo. Teratology 31:41-47

13. Hawkins JA, Hu N, Clark EB 1984 Effect of caffeine on cardiovascular function in the stage 24 chick embryo. Dev Pharmacol Ther 7:334-343

14. St Petery LB Jr, Van Mierop LHS 1977 Evidence for the presence of adrenergic receptors in 3-day-old chick embryo. Am J Physiol 232:H250-H254

15. Ignarro LJ, Shideman FE 1968 Appearance and concentrations of catecholamines and their biosynthesis in the embryonic and developing chick. $J$ Pharamcol Exp Ther 159:38-48

16. Wallace JA 1982 Monoamines in the early chick embryo. Demonstration of serotonin synthesis and regional distribution of serotonin-concentrating cells during morphogenesis. Am J Anat 165:261-274 